\title{
Aquino de Bragança: o intelectual e a independência de África ${ }^{1}$ Aquino de Bragança: the intellectual and the independence of Africa
}

\author{
AnNAmaria Gentili*
}

RESUMO: AQUINO DE BRAGANÇA, JORNALISTA, ACADÊMICO E MILITANTE DA LIBERTAÇÃO DA ÁFRICA, É FOCALIZADO EM ARTIGO QUE CONTEMPLA O SEU PERFIL NO CONTEXTO DAS INDEPENDÊNCIAS E NA SUA AÇÃO COMO FUNDADOR DO CENTRO DE ESTUDOS AFRICANOS DA UNIVERSIDADE EDUARDO MONDLANE.

ABSTRACT: JOURNALIST, PROFESSOR AND MILITANT OF THE AFRICAN LIBERATION, AQUINO DE BRAGANÇA IS ANALYSED IN THIS ARTICLE, THAT SHOWS YOUR PROFILE IN THE CONTEXTE OF THE INDEPENDENCES AND IN YOUR ACTION AS FOUNDER OF THE CENTRO DE ESTUDOS AFRICANOS AT UNIVERSIDADE EDUARDO MONDLANE.

PALAVRAS-CHAVE: AQUINO DE BRAGANÇA, INTELECTUAL, MOÇAMBIQUE, INDEPENDÊNCIA, CENTRO DE ESTUDOS AFRICANOS.

KEYWORDS: AQUINO DE BRAGANÇA, INTELLECTUAL, MOZAMBIQUE, INDEPENDENCE, CENTER OF AFRICAN STUDIES.

1. Em abril de 2009 realizou-se em Maputo um colóquio internacional em homenagem a Aquino de Bragança. Reunidas pelo CESAB (Centro de Estudos Sociais Aquino de Bragança), as comunicações compuseram um volume que, organizado por Teresa Cruz e Silva, João Paulo Borges Coelho e Amélia Neves de Souto, acaba de ser publicado pelo CODESRIA, em Dakar. O presente trabalho foi produzido para o referido livro como texto preliminar (VA).

* Universidade de Bologna, Bologna, Província de Bologna, Itália. E-mail: gentili@unibo.it 
as suas aulas - e até, mais frequentemente, nas conversas informais - Aquino oferecia-nos com prodigalidade ideias, motivos de inspiração, anedotas esclarecedoras sobre problemas e acontecimentos históricos e políticos, fazendoo com a autoridade de quem fala sobre assuntos que conhece bem, não só por os ter estudado, mas, sobretudo, por os ter vivido. Ele praticava com naturalidade a melhor forma de cortesia, que é a sincera curiosidade humana em relação aos outros, especialmente aos jovens, e por causa disso foi um grande professor e um jornalista sem igual. Muitos de nós beneficiámos desta sua generosidade, às vezes sem mesmo o notar.

Jacques Depelchin escreveu que a grande paixão política e intelectual de Aquino "era de procurar sempre respostas singulares para os desafios, não só do momento mas também do futuro". (DEPELCHIN, 2008)

Aquino não tolerava boatos nem boateiros, e a sua discrição acerca do que se discutia nos círculos do poder era total. Aquino gostava de falar, mas nunca sobre si. Preferia conhecer o ponto de vista dos interlocutores, instando-os com perguntas insinuantes. Não se contentando com as aparências, esquadrinhava o âmago dos factos e exortava todos, especialmente os jovens, a serem inquietos, a interrogarem-se, a formularem perguntas sempre mais ousadas, a controlarem minuciosamente as fontes. Quem teve o privilégio de o acompanhar na pesquisa de campo pode ser testemunha disso: em 1982, juntamente com Yussuf Adam, Colin Darch, Jacques Depelchin e Valdemir Zamparoni, no Planalto de Mueda, todos nós, que nos tínhamos por veteranos na pesquisa com as fontes orais, apercebemo-nos cedo que as suas perguntas eram as que despertavam as respostas mais estimulantes nos nossos interlocutores. Por outro lado, as suas aulas eram apaixonantes, capazes não só de esclarecer mas também de nos fazer participar nos acontecimentos e contextos por meio de um processo dialéctico que não deixava de lado nenhum aspecto do assunto examinado. Ele acreditava que as perguntas são mais importantes do que as respostas, e as suas eram sempre mais cultas, esclarecidas e empáticas do que as nossas.

Ainda hoje, muitos anos decorridos desde a sua trágica morte, sentimos (eu sem dúvida sinto) a sua falta. Muitas vezes tento imaginar como ele comentaria as mudanças ocorridas em Moçambique no contexto das convulsões que caracterizam a aceleração da globalização, e como, e onde, teria ele reconhecido progressos e retrocessos, desvendado os "interesses" envolvidos ou apontado as alternativas possíveis. Aquino estava convencido de que cada 
problema tinha mais soluções que a solução óbvia ou mais privilegiada de acordo com as relações de força prevalecentes na burocracia partidária e estatal, e que o seu e nosso dever de intelectuais era de estudar e apontar esses possíveis caminhos alternativos com base na recolha e análise dos dados, factos e opiniões sólidas, e por isso valia a pena incentivar a pesquisa em conjunto com a formação, tendo sempre como guia e finalidade a emancipação e a libertação das capacidades de desenvolvimento autónomo dos indivíduos e das classes mais vulneráveis.

Aquino nunca deixou de crer firmemente no primado da política. A sua vida foi preenchida pelo combate à discriminação colonial e pelo esforço para impedir que a luta de libertação nacional moçambicana ficasse contida dentro dos limites de um compromisso neo-colonial. Contra o colonialismo, as "manobras" neo-colonialistas e as estratégias para destruir a soberania conquistada com tanto esforço, Aquino asseverava ser preciso operar por meio de um trabalho científico infatigável de observação e análise das coisas, para se conquistar a liberdade e a emancipação sem perder nunca a esperança e a certeza de consegui-las. Possuía um pragmatismo destituído de timidez, mas que tinha sempre presente o sentido dos limites, daquilo que era possível num determinado momento histórico. Sabia indagar os sentidos e os contextos por nós utilizados no conceito do conhecimento. Tratando-se de um cientista por formação, o conhecimento era por ele entendido como opinião acompanhada da razão.

Considere-se a sua posição sobre o Acordo de Nkomati, ${ }^{2}$ expressa em artigos e palestras: sem triunfalismo algum, especificava a este respeito os passos que considerava essenciais para se poder fazer ouvir a voz de Moçambique num contexto internacional em rápida transformação, com o objectivo de se poder chegar a uma solução negociada que evitasse a derrota militar e, especialmente, a derrota política, e que acabasse com um conflito que era devastador para a população, e permitisse consolidar e relançar o que de positivo se havia conquistado, reinstalando a capacidade de contribuição para a derrota do regime de apartheid. Ele sabia que o caminho seria longo e que não existiam soluções imediatas, nem militares nem negociais. Quando o avião que levava Samora Machel

2. Acordo de não-agressão e de não-ingerência assinado entre a República Popular de Moçambique e o governo sul-africano do "apartheid" que na época suscitou grande polémica em África.(VA) 
e muitos dos seus ministros e conselheiros, entre os quais o próprio Aquino, foi abatido em Mbuzini, ele estava empenhado em colaborar para reatar os fios da negociação, sempre na perspectiva de acabar com a guerra. Na última vez em que o vi, em Harare, em Setembro de 1986, durante o Congresso dos Países Não-Alinhados, Aquino integrava a delegação moçambicana. Connosco estava Lisa Foa, uma amiga italiana, que Aquino considerava inteligente jornalista, observadora inquieta, participante em várias experiências de denúncia de formas de opressão, e com a qual gostava imensamente de discutir. (FOA, 2004) ${ }^{3} \mathrm{Na}$ quela altura, recorrendo como habitualmente a uma argumentação complexa, sem deixar de ser discreto, fez-nos entender que o momento era particularmente perigoso, e que, justamente, a retomada das negociações políticas estava a desencadear reacções cruzadas por parte daqueles que eram resolutamente hostis a qualquer solução política.

Aquino não tolerava os clichés, nem os dogmáticos acostumados à langue de bois, e, ainda que homem cultíssimo, não cedia a fazer história por analogia. Discutia a importância histórica das revoluções e das lutas de libertação do passado e do presente para a emancipação dos povos, salientando as suas contradições e condenando sem hesitação as derivas totalitárias. Insistia em sublinhar o carácter específico de cada luta política e/ou armada anti-colonial: "a análise revolucionária não se compadece com o apego a fórmulas feitas". Não acreditava num marxismo tornado "credo" ou "sistema", nem certamente num reductium ad unum dos factos históricos. O pensamento único não era traço marcante seu, e por isso aconteceu-lhe muitas vezes ser firme opositor de auto-proclamadas versões da ortodoxia marxista-leninista, tal como hoje aconteceria em relação a quem, da mesma forma acrítica, aderiu ao fundamentalismo liberal.

Ser historiador (e cientista social) é tarefa perigosa dos que acabam por oscilar entre ser considerados antagonistas ou, pelo contrário, instrumentos do poder. Aquino estava firmemente convencido de que a luta de libertação produzira em Moçambique elementos novos e não-comparáveis com os anteriores, e fundamentava nisso a sua convicção de que era possível e necessário contribuir, por meio da pesquisa e da formação, para os traduzir numa nova ordem estatal, política e ética.

3. Lisa Foa lembra Aquino como "um intelectual com grande preparação e experiência política". 


\section{As origens do Centro de Estudos Africanos}

Numa entrevista de Christiane Messiant a Mário de Andrade, em 1982, este último reconhecia no amigo Aquino, "um personagem importante do nosso caminho", salientando a abertura, a enorme cultura política e o facto de ele ser "um animal político dotado de grande curiosidade intelectual". Ele foi o primeiro deste grupo de intelectuais militantes pela causa da libertação das colónias portuguesas a regressar a África, especificamente a Marrocos, como professor e conselheiro do governo do Istiqlal e do sindicato. Amigo e conselheiro de Ben Barka, teve um papel central na preparação da conferência de 1961. Na altura do seu regresso à África, que antecedeu o importante ano de 1960, ano das independências africanas, Aquino já havia passado por muitas experiências e continentes, desde Goa até Lisboa e Paris, esta última, nos anos 50, verdadeira capital do mundo intelectual africano francófono, e encarava criticamente o processo de descolonização que conduziu às independências octroyées.

Entre 1945 e 1962 não houve ano em que a França não estivesse envolvida em guerras coloniais - desde a derrota da Indochina até à Argélia, passando pelas revoltas na África sub-sahariana, afogadas em sangue - em favor de compromissos neo-coloniais. Dos 17 países que se tornaram independentes em 1960, 14 eram ex-colónias francesas, e o termo neo-colonialismo foi inventado naquela altura para definir a continuidade da dependência em relação aos interesses franceses. Tornou-se célebre a piada do recentemente falecido presidente do Gabão, Omar Bongo: "A França sem a África é um carro sem carburante, e a África sem a França é um carro sem motorista". O coração das trevas desta aliança, que foi definida como Françafrique por Felix Houphouet-Boigny, foi a cumplicidade e o apoio activo que a França republicana, pátria do universalismo dos direitos humanos, deu à repressão e ao martírio dos líderes que contra ela se perfilavam: em Madagascar, entre 1947 e 1948, um governo francês chefiado por um primeiro-ministro socialista foi responsável pela repressão duma insurreição que provocou mais de cem mil mortos. Nos Camarões, o presidente Ahidjo, homem escolhido pelos franceses em lugar de André-Marie Mbida, exterminou todas as oposições; os chefes rebeldes da Union des Populations du Cameroun foram eliminados com brutalidade, Rum Nyobé foi trucidado em 1958 e Félix Moumié envenenado em 
Geneva com barbouze. A independência da Guiné-Conacri em 1958, contra a vontade da França, provocara já o ostracismo e sanções pesadas contra este país. Quem mostrou intenções de querer operar uma viragem em direcção a uma política de maior autonomia, como Sylvanus Olimpio no Togo, foi vítima de eliminação política e física manu militari.

Em Paris, Aquino participava da atmosfera estimulante que florescia em torno da Présence Africaine, aderia à denúncia radical da hipocrisia das potências coloniais europeias nos Discours sur le colonialisme de Aimé Césaire, e compartilhava a reivindicação da historicidade dos mundos africanos. Desde essa altura que o francês vai constituir a sua língua de eleição. Para além dos limites do mundo e da intelectualidade de língua portuguesa e francesa, com o regresso à África, e com a sua actividade de jornalista, Aquino estabeleceu relações de amizade e solidariedade com figuras importantes do mundo anglófono e não só, nomeadamente com o Gana, independente desde 1957 sob a liderança do carismático Kwame Nkrumah, porta-voz de um nacionalismo pan-africano moderno, radical, representando a emergência de homens oriundos de camadas intelectuais urbanizadas, convencidos de que para conquistar a liberdade e a soberania plena tinha de se desmantelar a estrutura fundamental dos estados coloniais representada por sistemas administrativos de governo que visavam a promoção de uma independência balcanizada. Após a independência, já em 1958, e a fim de revalidar o papel de liderança, Nkrumah havia promovido a All Africa People's Conference, que adoptou o slogan "Hands off Africa! Africa must be free”. Nela participaram 28 delegações africanas, entre as quais se destacavam líderes que desempenhavam mais decisivamente uma oposição crítica ao colonialismo, tais como Patrice Lumumba, Julius Nyerere, Namdi Azikwe, Ahmed Ben Bella e Kenneth Kaunda. Naqueles anos, Accra tornou-se a capital do sonho e da esperança em relação a uma verdadeira emancipação. Em Janeiro, sempre na capital do Gana, foi pronunciado pela primeira vez o famoso discurso sobre os "Winds of change" de Harold MacMillan, primeiro-ministro inglês de um governo conservador, pressionado pelo Labour Party no interior e pelos movimentos nacionalistas africanos, e enfraquecido internacionalmente pelas revelações sobre as atrocidades cometidas durante a repressão dos Mau-Mau no Kenya. A convicção de que, para além de realista era sem dúvida mais conveniente para os interesses britânicos acelerar a descolonização, foi confirmada em Fevereiro em Cape Town, no 
parlamento do regime do apartheid, que reagiu com uma recusa total e com a decisão de proclamar a república e de dar força à guerra total contra qualquer contestação possível ou movimento político de emancipação. Aquino viveu de perto todos estes acontecimentos e seguiu também de perto as vicissitudes da primeira independência do Congo-Kinshasa. O assassinato de Patrice Lumumba, cuja denúncia dos crimes da colonização belga e reivindicação do direito a uma independência que significasse o reconhecimento pleno de dignidade e igualdade para a população congolesa foram interpretadas como um desafio destinado a arredar os desígnios de uma independência apenas aparente, constituiu uma advertência trágica a toda a África. Contra ele e os seus ministros mais fiéis foi organizada uma caluniosa campanha de imprensa, prelúdio do desenvolvimento de cumplicidades entre os serviços secretos americanos, belgas e franceses - preocupados que o contágio nacionalista influenciasse o contíguo Congo-Brazzaville, cofre-forte do petróleo - activando redes e financiamentos de ingentes interesses económicos que se alastraram desde as alianças entre multinacionais estrangeiras até os poderes locais.

No curso da sua vida, desde Goa, Lisboa e Paris, até Marrocos e Argélia - e em contacto com as redes de reflexão e activismo político engajadas no apoio à emancipação do que então se chamava o terceiro mundo, assim como no seu trabalho de jornalista militante, que o fizera ganhar a confiança de todos os principais protagonistas das lutas políticas de libertação, desde Nkrumah a Nyerere - Aquino desempenhou um papel de primeira ordem com a sua riquíssima análise dos acontecimentos e das conjunturas específicas locais, entrelaçadas com as dinâmicas regionais e globais. Dos seus escritos jornalísticos emerge a centralidade da política como luta pelo controle e pela transformação do Estado, a atenção costante às motivações e redes de interesse económicas, e a importância de um método interdisciplinar. ${ }^{4}$

Ao longo da década de 60, as grandes esperanças suscitadas pelas independências africanas começaram a desvanecer-se. Seguiram-se os golpes mi-

4. Um trabalho ainda por fazer consiste na releitura dos seus numerosíssimos e consistentes artigos surgidos desde finais dos anos 60 na Africasia, Afrique-Asie, L'économiste du tiers monde, e noutras revistas, muitas vezes traduzidos em várias línguas. Além disso, Aquino tinha um arquivo de entrevistas com protagonistas das independências africanas, nunca completamente publicadas, em que trabalhava pouco antes da sua morte. Como diz o seu amigo Luís Filipe Pereira, nunca mais foi encontrado esse arquivo. 
litares e derivas autoritárias, favorecidas pela conclusão da fase de expansão económica mundial e pelo endurecimento da guerra fria. A fragilidade das estruturas dos Estados pós-coloniais, as heranças negativas, as assimetrias herdadas da dominação colonial, contribuiram para tornar evidentes as caracterísicas das crises africanas, manifestações do inelutável espraiar de uma série de contradições enraizadas na história de dominação colonial e, sobretudo, nas formas ambíguas da descolonização que favoreciam o estabelecimento e a consolidação das prioridades da guerra fria, que permaneceram como estratégia principal de incorporação do continente, seja como for, mantendo sempre, em certa medida, esses Estados numa posição de dependência em relação a uma ou outra potência mundial.

Em 1960, Amilcar Cabral, que em todos os seus escritos sublinhou a importância do conhecimento, da pesquisa e da formação, incitava os companheiros da luta a voltar à África. As lutas de libertação na Guiné-Bissau e na África Austral, ou seja, no contexto de uma região dominada pelo regime sul-africano do apartheid, representaram o relançamento do projecto de emancipação, de "uma independência sem qualquer ambiguidade, uma independência sem descolonização e sem a imposição de um regime neocolonial". (BRAGANÇA, 1986, p. 9)

\section{Centro de Estudos Africanos: pesquisa para a formação}

O Centro de Estudos Africanos em Maputo é pensado e organizado neste contexto político e de conhecimento, e tira a inspiração também da organização de programas académicos centrados nas ciências sociais activados desde a década de 60 em várias universidades africanas, de Dakar a Dar Es Salaam. As perspectivas metodológicas e teóricas por meio das quais se analisavam as realidades africanas já tinham sido postas em questão, desafiadas pela crítica que evidenciava as suas bases conceptuais ainda enraizadas nas ideologias do colonialismo. Para os intelectuais africanos, o desafio principal consistia em reconhecer simultaneamente a especificidade dos processos de evolução histórica e dos interesses que orientavam as metrópoles, e a reivindicação da historicidade das sociedades africanas, assim como o direito à plena emancipação. 
O modelo de formação intimamente ligado à pesquisa, que vai caracterizar o Centro de Estudos Africanos, não pode ser percebido na sua essência se não for reconhecida previamente a sua pertença, e mais tarde a sua contribuição ao vasto movimento internacional africano e pan-africano, votado a redefinir radicalmente o ensino da história e das ciências sociais como instrumento de resgate e de soberania. Justamente pela sua experiência política e profissional cosmopolita, Aquino concebia o Centro de Estudos Africanos como um centro não só de reflexão epistemológica - onde o nosso saber, mas também o de outrém, fosse continuamente posto em questão - mas também de formação, sem modelos pré-estabelecidos e buscando inspiração em experiências mais avançadas cujo horizonte era, decisiva e explicitamente, o de contribuir para uma transformação social emancipatória.

O projecto do Centro partia de um conjunto de valores essenciais elaborados e enraizados na luta de libertação: proteger e tornar real a liberdade tão duramente conquistada, crer firmemente na igualdade, apoiar com os recursos da pesquisa e da formação a vontade e a capacidade de acção da liderança e do governo de Moçambique. Por isso a pesquisa de campo se tornou essencial, não só para recolher dados reais que, analisados, permitiam conceber e melhorar as políticas administrativas, económicas e distributivas, mas também para tomar conhecimento concreto das condições e percepções dos problemas das populações. Ainda que mais não proporcionasse, a pesquisa começou a quebrar a retórica ideológica com que se falava dos problemas, e a pôr em destaque que se a liderança política e os intelectuais empenhados e solidários pareciam saber perfeitamente o que deveria nascer das cinzas do Estado colonial, a maioria deles ignorava de facto o que era o Estado colonial. Por isso, o Curso de Desenvolvimento do CEA fundou-se na recolha e na análise dos dados sobre a estrutura e a dinâmica da mudança numa situação concreta, a moçambicana, com as suas características locais, nacionais e de contexto regional, identificando as suas tendências específicas, contraditórias e por vezes antagónicas, que a ideologia não reconhecia ou até demonizava, com o fim de elaborar e discutir prioridades e possíveis soluções.

O Curso contribuiu imensamente para a formação dos quadros: por causa da situação colonial, muitos dos estudantes tinham uma instrução formal de baixo nível, mas desempenhavam papéis de responsabilidade em vários sectores públicos. O método de ensino, sem descurar as aulas de formação 
básica dadas por professores de grande experiência e capacidade, fundava-se em determinar cuidadosamente a relevância de um problema e na maneira de apontar soluções idóneas para cada contexto. Foram muitos os desafios que surgiram, no âmbito da organização de métodos de ensino destinados a estudantes com diferentes níveis de formação, visando que se pusessem a par e adquirissem confiança, forma de os encorajar a participar e a colocar questões. Em lugar de os intimidar ou utilizar como mão-de-obra de baixo custo, pretendia-se envolvê-los na teorização, na organização e na condução e redacção dos trabalhos de pesquisa.

Foi Aquino quem escolheu Ruth First ${ }^{5}$ como directora de pesquisa. Duas personalidades diferentes, mas unidas por uma sólida e antiga amizade, e por admiração e respeito recíprocos. Em Ruth, Aquino admirava a inteligência brilhante, a capacidade de síntese, a honestidade absoluta, a dedição à causa de Moçambique, e também a sua elegância. Longe de ser uma marxista dogmática, Ruth compartilhava com Aquino a crítica ao totalitarismo das revoluções soviética e chinesa, mas também não tolerava o egocentrismo da esquerda dos intelectuais de salão. Nunca ouvi Aquino criticar Ruth em público; quanto a Ruth, dedicava a Aquino grande devoção e admiração. Os dois não toleravam a retórica, mantinham mentes livres que compartilhavam o mesmo horizonte político. Eram, claro, muito diferentes no carácter e no estilo: Aquino exercia a arte de intervir e criticar (mesmo duramente) utilizando luvas de pelica, enquanto ela achava indigesta a diplomacia, tinha uma maneira de argumentar directa, por vezes mesmo áspera e impaciente, e isto criava incompreensões que depois a faziam sentir vulnerável. Os dois, antes de o serem com os outros, eram exigentes consigo próprios, não aceitavam um trabalho mal feito. Não só Ruth, mas também Aquino, raramente ficavam satisfeitos com os textos redigidos e quase sempre era preciso reescrevê-los várias vezes. Em certas ocasiões Aquino mostrava-se abertamente irritado, e não se socorria da sua requintada veia diplomática: em particular quando lia traduções de textos em português que achava desprovidas de fineza conceptual.

5. Proeminente intelecual e militante anti-apartheid de nacionalidade sul-africana, assassinada em seu escritório na Universidade Eduardo Mondlane, por uma carta-bomba enviada pelos serviços secretos sul-africanos. 
Quem deduziu, a partir de uma observação superficial do ambiente de trabalho, que Aquino e Ruth tinham conflitos importantes, sem dúvida não percebeu aquilo que os tornava fundamentalmente solidários, para além das diferenças caracteriais: o facto de desde jovens terem sido, como Aquino dizia, "compagnons de route", e de estarem ambos empenhados em contribuir para o trabalho de instituições que queriam produzir mudança. Os dois, e da mesma forma todos os que optaram por trabalhar no Centro, achavam que isso não significava a subordinação a um desígnio superior nem aquiesciência cega à ideologia no poder, mas antes, e constantemente, colocar-se a pergunta de como contribuir melhor para o progresso da luta emancipatória, e interrogarse permanentemente sobre como melhorar a maneira de trabalhar, de fazer pesquisa, de ensinar. Em 1977, Ruth escrevia, de Maputo, a Gavin Williams: "there are gaps in our strategies; we can only hope to close them in practice; that means being where policies are made and influenced; it also requires a practical understanding of the problem so we can offer alternatives when policies don't work out'. (WILLIAMS, 1982)

Em nenhum momento as decisões sobre as mudanças no Curso de Desenvolvimento, ou nas opções de pesquisa, foram tomadas ou impostas por Ruth. Aquino foi sempre o "comandante-em-chefe" e o indispensável negociador e garante de uma pesquisa livre de condicionamentos.

O Centro, onde afluíam pesquisadores de muitas partes da África e do mundo, era um espaço poliglota de especialistas em disciplinas e tendências intelectuais diversas, mas politicamente empenhados. Ao contrário do que alguns pretendem fazer crer, nunca foi transformado num espaço de pensamento único. Foi antes, como diria Aquino, um espaço onde espíritos inquietos enfrentavam as suas diversidades, ainda que solidários na finalidade de contribuir para remover ou ultrapassar as limitações impostas pela subordinação colonial, e para apoiar o crescimento de uma capacidade de desenvolvimento autónoma. O Centro não era um "mundo à parte" no contexto académico e de Moçambique, antes contribuiu para transformar esse contexto e torná-lo conhecido através daqueles que ali foram formados, e que em seguida tiveram a oportunidade de se integrar com sucesso em outros ambientes culturais, muitas vezes elaborando mesmo, neste percurso, posições críticas a respeito daquela fase por que passaram.

O Centro caracterizava-se pela simbiose entre pesquisa e formação no Curso de Desenvolvimento, cuja organização era em cada ano renovada. A mim 
nunca mais me aconteceu viver uma experiência de pesquisa tão significativa, e sem dúvida que aprendi mais do que aquilo que fui capaz de contribuir. No Centro investiu-se em novas abordagens metodológicas, experimentou-se um novo género de formação, desenvolveram-se categorias analíticas e argumentações teóricas para interpretar condições históricas concretas de trabalho e produção em Moçambique, no contexto regional. Investigou-se sobre os aspectos problemáticos da questão rodesiana e sobre o significativo impacto do factor migratório sobre as sociedades de proveniência dos migrantes. Aprendeu-se a dar valor à prática da reciprocidade, à responsabilidade para com as pessoas que participavam no trabalho de pesquisa, incorporando estudantes, camponeses, migrantes, trabalhadores, mulheres e jovens no processo de teorização, levando a que as pessoas não fossem reduzidas a meras informadoras sobre dados e factos, mas antes levadas a sério ao nível conceptual.

O apelo de Carlos Cardoso acerca da necessária integração entre a dimensão do conhecimento e as dimensões ética e política, e o de Elísio Macamo que incita a aprofundar o pensamento de Aquino, de produção de um saber fundado na experiência mas atento à história, põem-nos face à responsabilidade de perceber, sem nos deixarmos desencorajar pelas derrotas e pelos pessimismos, a essência daquela metodologia de ensino. Aquino acreditava no progresso - não com uma fé cega, mas com uma convicção reforçada pela história e pela experiência da prática como prévia à teoria, e, sobretudo, acreditava que cada um tinha de se empenhar em realizar esse progresso sem desfalecimentos, mesmo quando a mudança - como aconteceu muitas vezes no passado e certamente vai continuar a acontecer no futuro - se manifesta em retrocessos, revelando divergências profundas entre os significados concretos do desenvolvimento hoje em África, tendo como horizonte a sorte das classes mais desfavorecidas e vulneráveis, qualquer que seja a natureza do sistema mundial que condicionou e continua a condicionar o terreno das escolhas e das opções possíveis; reflectir, investigar e discutir também os resultados do processo de democratização na progressiva extensão dos direitos e da participação, à qual contudo parece corresponder o languescer da dialéctica política; e finalmente, discutir como e quanto as reformas económicas e sociais abrem direitos de acesso concreto a uma cidadania igualitária, para perceber a configuração das forças sociais, no acto reintegrando a complexidade no lugar onde a simplificação de um modelo único parece guiar e justificar qualquer acção. 


\section{Referências Bibliográficas}

BRAGANÇA, Aquino de. Independência sem descolonização: a tranferência do poder em Moçambique: 1974-1975. Notas sobre os seus antecedentes. In: Estudos Mocambicanos, Maputo, n. 5/6, p. 9, 1986.

DEPELCHIN, Jacques. Porque falar do Aquino de Bragança (AB)? In: Pambazukanews, 19 de Abril de 2008. Disponível em http://pambazuka.org/pt/category/features/47521/print. Acesso em 28 de Março de 2011.

FOA, Lisa. Ė andata cosi. Palermo: Sellerio Editor, 2004.

WILLIAMS, G. Ruth First is dead. In: New Society, [s.p.], August 1982.

Recebido em 02 de maio de 2012 e aprovado em 28 de maio de 2012. 